\title{
PROTOTIPE MOBILE STATION UNTUK PEREKAMAN KANDUNGAN UDARA
}

\author{
Gusti Ketut Bella ${ }^{1}$ Nyoman Putra Sastra ${ }^{2}$, I G. A. K. Diafari Djuni Hartawan ${ }^{3}$ \\ Program Studi Teknik Elektro, Fakultas Teknik, Universitas Udayana \\ Email: bellawidya70@@gmail.com $\underline{1}$, putra.sastra@unud.ac.id $\underline{2}$, igakdiafari@unud.ac.id ${ }^{3}$
}

\section{ABSTRAK}

Penelitian ini bertujuan untuk memantau kualitas udara kota Denpasar dengan mobile station yang dapat mengirimkan informasi kandungan udara secara mobile dan real time. Mobile station ini dibangun menggunakan Wemos D1 Mini Board yang merupakan board wifi kecil berbasis ESP8266. Informasi yang dikirim melalui board Wemos D1 adalah informasi yang didapatkan dari sensor MQ-7 dan MQ-135 dan DHT11. Sensor DHT11, MQ-7 dan MQ-135 dapat mendeteksi suhu, gas $\mathrm{CO}$ dan gas $\mathrm{NH}_{3}$, $\mathrm{NOx}$, alcohol, benzene, smoke dan $\mathrm{CO}_{2}$. Informasi yang diperoleh dari sensor akan dicantumkan pada sebuah website sehingga masyarakat dapat mengetahui tingkat polusi udara di kota Denpasar. Sistem pemantauan yang telah dikembangkan ini telah berhasil menampilkan data dalam bentuk map pada jendela web.

Kata Kunci : Pencemaran udara , Mobile Station ,MQ-7, MQ-135, DHT11, dan Mikrokontroller Wemos D1

\section{ABSTRACT}

This study aims to monitor the air quality of Denpasar city with mobile station that can transmit air content information in mobile and real time. This mobile station was built using Wemos D1 Mini Board which is a small wifi board based on ESP8266. Information sent via the Wemos D1 board is information obtained from sensors MQ-7 and MQ-135 and DHT11. DHT11, MQ-7 and MQ-135 sensors can detect the temperature, $\mathrm{CO}$ and NH3 gas, NOx, alcohol, benzene, smoke and CO2. Information obtained from the sensors will be posted on a website so that people can know the level of air pollution in the city of Denpasar. This developed monitoring system has successfully displayed data in the form of a folder on the web server.

\section{Key Words : Air Pollution ,Mobile Station ,Mq-7, Mq-135, Dht11, And Microcontroller Wemos D1}

\section{PENDAHULUAN}

Pencemaran udara merupakan kondisi ketika kualitas udara menjadi rusak dan terkontaminasi oleh zat-zat yang tidak baik bagi kesehatan manusia. Pencemaran udara terjadi akibat pembakaran yang tidak sempurna dari mesin kendaraan maupun proses industri yang menghasilkan gas-gas yang mengandung zat yang tidak baik bagi kesehatan akibat dari pembakaran yang tidak sempurna[1] Pencemaran udara tersebut menyebabkan penurunan kualitas udara yang berdampak negatif pada kesehatan manusia. $\mathrm{Hal}$ ini menjadi isu lingkungan yang terutama berdampak pada wilayah perkotaan. Begitu juga dengan kota Denpasar yang merupakan kota dengan tingkat kepadatan kendaraan yang tinggi terjadi pencemaran udara.

Berdasarkan laporan SLH dan pemantauan data ISPU, beberapa kota di Indonesia yang memiliki potensi tingkat polusi udara yang tinggi tidak mengoperasikan stasiun pengamat polusi udara. Hal ini terjadi pada beberapa stasiun pengamat polusi udara 
di provinsi Bali yang di dalamnya termasuk kota Denpasar [2]. Sehingga upaya untuk mempermudah pemerintah dan masyarakat dalam mengetahui tingkat polusi udara tidak dapat terwujud dengan baik.

Untuk membantu upaya memonitor tingkat polusi udara di kota Denpasar, perlu dibuat station-station pemantau kualitas udara yang dapat memberikan informasi secara real time. Pada penelitian ini dipaparkan ide untuk membuat mobile station yang dapat mengirimkan informasi kandungan udara secara mobile dan real time. Mobile station ini dibangun menggunakan Wemos D1 Mini Board yang merupakan board wifi kecil berbasis ESP8266 [3]. Informasi yang dikirim melalui board Wemos D1 adalah informasi yang didapatkan dari sensor MQ-7 dan MQ135. Sensor MQ-7 dan MQ135 dapat mendeteksi gas $\mathrm{CO}$ dan gas $\mathrm{NH}_{3}, \mathrm{NOx}$, alcohol, benzene, smoke dan $\mathrm{CO}_{2}$ yang merupakan hasil dari gas emisi kendaraan bermotor, limbah industri, gas polutan lainnya. Informasi yang diperoleh dari sensor akan dicantumkan pada sebuah website sehingga masyarakat dapat mengetahui tingkat polusi udara di kota Denpasar. Sehingga diharapkan timbul kesadaran untuk turut serta menjaga dan melestarikan lingkungan.

\section{DESAIN SISTEM}

Gambar 1 merupakan model mobile station ini, yang terdiri dari, Sensor DHT11, Sensor MQ-7, Sensor MQ-135, GPS , Mikrokontroller Wemos D1, Modul ESP8266, Web Server, dan Database Server.

- 4 oleh sensor DHT11, MQ7, dan MQ-135 akan disimpan sementara oleh Wemos D1. Selanjutnya data sensor tersebut akan dikirimkan menggunakan WiFi, ESP8266, yang telah terhubung dengan SSID. Pada sistem ini, SSID atau akses point didapatkan dari perangkat HP yang dapat berfungsi sebagai Access Point. Selain ketiga data sensor tersebut, agar dapat mengirimkan data spasial, maka digunakan juga perangkat GPS. Dari terminal GPS ini, diperoleh koordinat titik ketika data tersebut diambil dari sensor-sensor tersebut. Data dari sensor dan data spasial dari GPS yang terkirim melalui WiFi akan menuju server tempat aplikasi spasial berupa google MAP.

\subsection{Jaringan Sensor Nirkabel}

Jaringan Sensor Nirkabel, Gambar 2 adalah sebuah jaringan komunikasi sensor yang terhubung secara wireless atau nirkabel untuk memberikan informasi kondisi fisik maupun kondisi lingkungan tertentu pada lokasi yang berbeda. Pemrosesan data dan hasil tangkapan sensor biasanya terdistribusi [4].

JSN (Jaringan Sensor Nirkabel) terdiri dari empat komponen yaitu sensor node, media nirkabel, nodal koordinator/gateway dan PC server/administrator.

Wireless Sensor Network

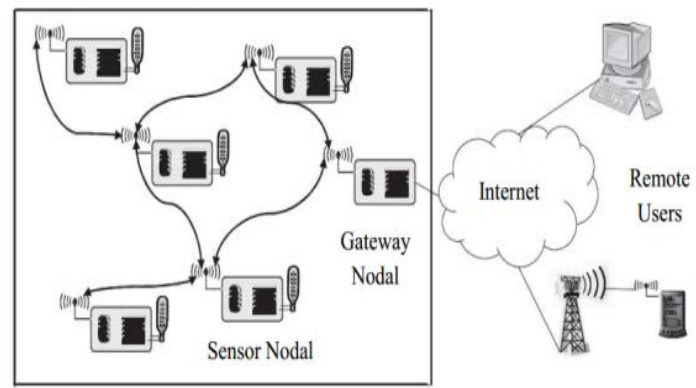

Gambar 2. Komponen Dasar JSN

\section{$2.2 \quad$ Wi-Fi}

Wi-Fi atau Wireless Fidelity yaitu

sebuah teknologi yang memanfaatkan peralatan elektronik untuk bertukar data secara nirkabel (menggunakan gelombang

radio) melalui sebuah jaringan komputer,
Gambar 1. Rancangan Hardware Alat Secara umum data yang ditangkap 
termasuk koneksi internet berkecepatan tinggi. Wi-Fi Alliance mendefinisikan $\mathrm{Wi}-\mathrm{Fi}$ sebagai produk Local Area Network (LAN) yang didasarkan pada standar Institute of Electrical and Electronics Engineers (IEEE) 802.11. Ada empat variasi dari 802.11 yaitu 802.11a, 802.11b, 802.11g, 802.11n.

\subsection{Mikrokontroler Wemos D1 Mini dilengkapi Modul WiFi ESP8266}

ESP8266 adalah sebuah modul WiFi dengan platform SOC. Wemos Mini D1 merupakan sebuah mikrokontroler hasil pengembangan berbasis modul ESP8266. ESP8266 ini bisa menghubungkan perangkat mikrokontroller seperti arduino dengan internet via WiFi. Modul ESP8266 sudah terpasang pada mikrontroler Wemos D1 mini. Wemos D1 sendiri dapat diprogram dengan menggunakan Arduino IDE sehingga memudahkan pengguna untuk melakukan upload firmware. Wemos D1 mini juga dapat diuji coba dengan ESPlorer, namun untuk memudahkan programming lebih mudah dilakukan dengan Arduino IDE. Dapat dilihat pada Gambar 3.

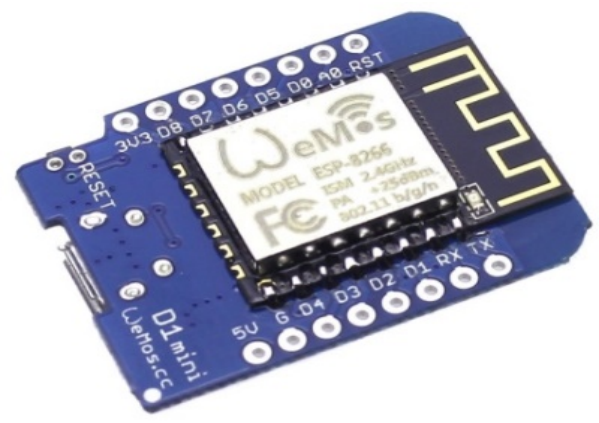

Gambar 3. Bentuk Fisik Wemos D1 Mini

\section{HASIL DAN PEMBAHASAN}

4.1 Hasil Penelitian

Hasil dari penelitian berupa sebuah perangkat yang ditunjukkan pada Gambar 4. Mikrokontroler yang digunakan pada rancangan adalah Wemos D1. Wemos D1 ini sebelum beroperasi akan di upload program terlebih dahulu menggunakan USB.

Sensor yang dirangkai pada $\mathrm{PCB}$ mempunyai fungsinya masing-masing, sensor
DHT11 untuk mengukur suhu dan kelembaban sensor MQ-7 untuk mendeteksi gas CO, sensor MQ-135 untuk mendeteksi gas $\mathrm{CO}$ dan gas $\mathrm{NH}_{3}$, NOx, alcohol, benzene, smoke dan $\mathrm{CO}_{2}$. Kemudian GPS yang berguna untuk menentukan lokasi. Semua sensor mendapat tegangan yang sama dari Wemos yaitu $5 \mathrm{~V}$.

Pada perangkat ini menggunakan powerbank 5V. Sehingga penggunaan powerbank pada rangkaian dengan di hubungkan ke alat. Penggunaan powerbank ini setelah program selesai di unggah ke mikrokontroler Wemos D1.

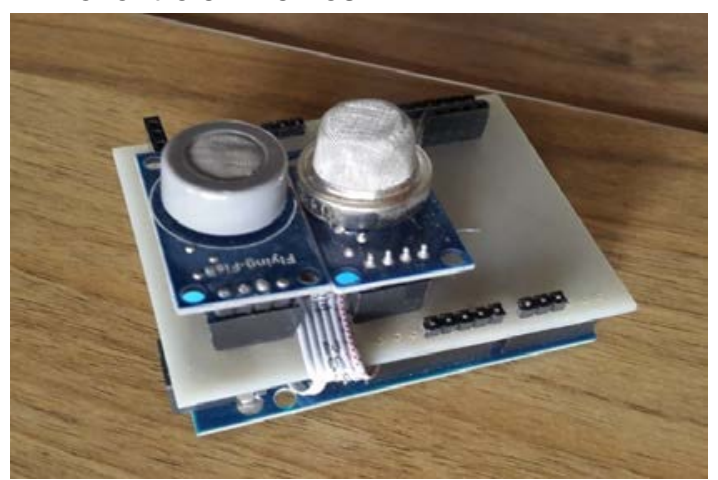

Gambar 4. Hasil Rancangan Keseluruhan

Perangkat

\subsection{Pembahasan Perangkat}

Pembahasan perangkat akan dilakukan dengan melakukan transmisi data sensor ke web server berupa tampilan map.

\subsubsection{Pengiriman data ke Web server}

Untuk penyajian data digunakan web server gtrack789.000webhostapp.com, yang akan menampilkan hasil sensor dalam bentuk map. Data yang ditangkap sensor-sensor akan dikirim melalui jaringan WiFi menggunakan modul ESP8266 yang terkoneksi dengan SSID yang ada di handpone untuk diteruskan ke server web. Sehingga dapat muncul di aplikasi spasial yang telah dibuat.

Pengujian dilakukan selama 1 jam tiap daerah dengan mobile station menggunakan sepeda motor dan hasilnya akan dikeluarkan setiap 5 detik selama 
pengujian atau perjalanan. Dari hasil pengujian didapat data hasil pada map yang ditampilkan pada public view gtrack789.000webhostapp.com.

Gambar 5 adalah tampilan data pada web untuk pengujian alat di daerah gunung lumut

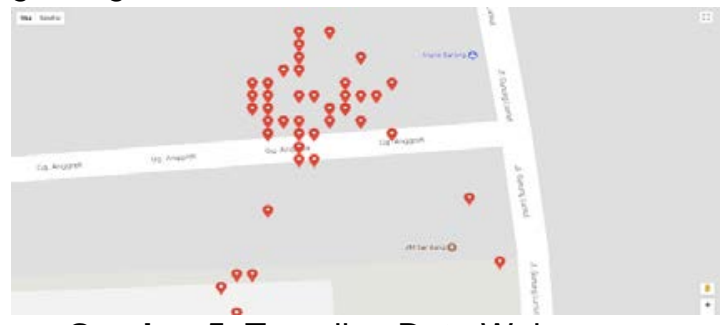

Gambar 5. Tampilan Data Web

Daerah Gunung Lumut.

Gambar 6 adalah tampilan data pada web untuk pengujian alat di daerah Teuku Umar.

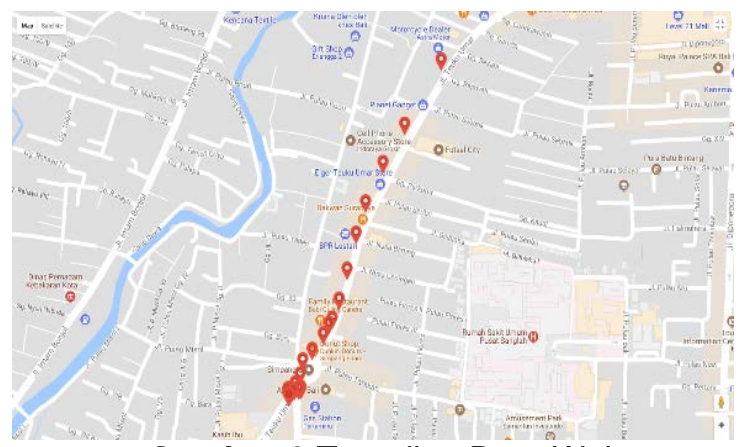

Gambar 6 Tampilan Data Web Daerah Teuku umar.

Gambar 7 adalah tampilan data pada web untuk pengujian alat di daerah Renon.

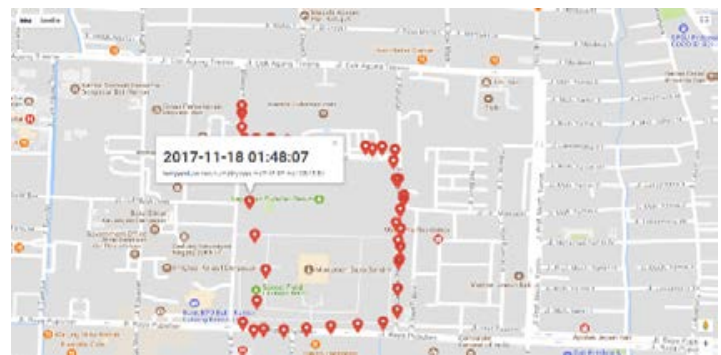

Gambar 7 Tampilan Data WebDaerah Renon

\subsection{Pengujian Perangkat}

Perancangan Perangkat menggunakan bahasa pemrograman Arduino dengan standar bahasa pemrograman mikrokontroler. Software yang digunakan pada alat perekaman kandungan udara berbasis mikrokontroler Wemos D1 dibuat dengan software Arduino IDE versi 1.6.9. Kemudian program di upload sehingga data dikirim menggunakan WiFi ESP8266 yang ada pada Wemos D1. Kemudian data yang didapat dari sensor akan dikirim melalui jaringan WiFi melalui access point, kemudian dikirim ke gtrack789.000webhostapp.com dan langsung dapat mengaksesnya ke web tersebut. Pengujian perangkat akan dilakukan secara mobile station. Kemudian Alat akan diletakkan pada sepeda motor dan dibawa keliling atau mobile station untuk mendeteksi gas polusi pada udara. Alat ini dirancang dalam sebuah kotak berbentuk mini agar memudahkan pengguna sepeda motor saat dibawa keliling. Terdapat 3 daerah pada saat pengujian yaitu Daerah Gunung Lumut, Teuku Umar, dan Renon. Pengujian perangkat.

\subsubsection{Hasil Uji Alat di Daerah Gunung Lumut}

Alat yang sudah diuji di daerah Gunung Lumut memperoleh berbagai macam nilai suhu dan kadar polusi udara yang telah di deteksi secara realtime. Rata-rata yang diperoleh pada pengujian ini yaitu MQ-7: 8304 dan MQ-135: 1577 berikut hasil pengujian alat prototipe Mobile Station untuk Perekaman Kandungan Udara. Hasil pengujian alat di daerah Teuku Umar dapat dilihat pada Tabel 1.

Tabel 1. Hasil Uji Alat Daerah Gunung Lumut

\begin{tabular}{|c|c|c|c|c|}
\hline \multirow{2}{*}{ No } & Mq7 & Mq135 & Temp & Hum \\
\cline { 2 - 5 } & $\mathbf{p p m}$ & $\mathbf{p p m}$ & ${ }^{\circ} \mathbf{C}$ & $\mathbf{R H}$ \\
\hline 1 & 264.96 & 33.62 & 31.07 & 73 \\
\hline 2 & 261.04 & 33.62 & 31.07 & 73 \\
\hline 3 & 249.6 & 28.34 & 31.07 & 73 \\
\hline 4 & 245.89 & 30.89 & 31.07 & 73 \\
\hline
\end{tabular}




\begin{tabular}{|c|c|c|c|c|}
\hline 5 & 238.6 & 30.24 & 30.94 & 72 \\
\hline 6 & 228.02 & 28.96 & 30.94 & 72 \\
\hline 7 & 224.58 & 26.54 & 30.94 & 72 \\
\hline 8 & 217.85 & 25.97 & 30.94 & 72 \\
\hline 9 & 208.07 & 26.54 & 30.94 & 72 \\
\hline 10 & 208.07 & 22.70 & 30.94 & 72 \\
\hline 11 & 198.68 & 23.22 & 32.91 & 71 \\
\hline 12 & 198.68 & 25.40 & 30.80 & 71 \\
\hline 13 & 195.63 & 24.84 & 30.80 & 71 \\
\hline 14 & 183.83 & 25.40 & 30.80 & 71 \\
\hline 15 & 183.83 & 24.84 & 30.80 & 71 \\
\hline 16 & 180.98 & 24.29 & 30.80 & 71 \\
\hline 17 & 178.16 & 24.29 & 30.80 & 71 \\
\hline 18 & 178.16 & 23.22 & 30.80 & 71 \\
\hline 19 & 172.64 & 22.70 & 30.94 & 72 \\
\hline 20 & 175.38 & 22.19 & 30.80 & 71 \\
\hline 21 & 156.96 & 19.76 & 30.80 & 71 \\
\hline 22 & 167.27 & 19.30 & 30.80 & 71 \\
\hline 23 & 164.64 & 21.19 & 30.80 & 71 \\
\hline 24 & 162.05 & 19.76 & 30.80 & 71 \\
\hline 25 & 147.19 & 20.71 & 30.80 & 71 \\
\hline 26 & 154.47 & 17.55 & 30.80 & 71 \\
\hline 27 & 152.01 & 20.23 & 30.80 & 71 \\
\hline 28 & 149.59 & 19.76 & 30.80 & 71 \\
\hline 29 & 147.19 & 19.30 & 30.80 & 71 \\
\hline 30 & 133.51 & 19.30 & 30.80 & 71 \\
\hline 31 & 142.51 & 16.72 & 30.80 & 71 \\
\hline$\Sigma$ & 8304.2 & 1080 & 1577 & 3641 \\
\hline
\end{tabular}

Umar

Alat yang sudah diuji di daerah Teuku Umar memperoleh berbagai macam nilai suhu dan kadar polusi udara yang telah di deteksi secara realtime. Adapun nilai rata-rata yang didapat yaitu MQ-7: 5108.3 dan MQ-135: 3743.44 Berikut hasil pengujian alat Prototipe Mobile Station untuk Perekaman Kandungan Udara. Hasil pengujian alat di daerah Teuku Umar dapat dilihat pada Tabel 2.

Tabel 2. Hasil Uji Alat Daerah Teuku Umar

\begin{tabular}{|c|c|c|c|c|}
\hline & Mq7 & Mq135 & Temp & Hum \\
\hline & ppm & ppm & ${ }^{\circ} \mathrm{C}$ & $\mathbf{R H}$ \\
\hline 1 & 103.91 & 132.92 & 32.36 & 68 \\
\hline 2 & 102.15 & 130.24 & 33.66 & 64 \\
\hline 3 & 102.15 & 130.89 & 33.66 & 64 \\
\hline 4 & 193.73 & 132.23 & 33.66 & 64 \\
\hline 5 & 197.02 & 132.23 & 33.66 & 64 \\
\hline 6 & 316.08 & 186.72 & 33.88 & 65 \\
\hline 7 & 316.08 & 172.64 & 33.66 & 65 \\
\hline 8 & 285.30 & 135.71 & 33.66 & 64 \\
\hline 9 & 249.60 & 109.34 & 33.66 & 64 \\
\hline 10 & 235.03 & 102.15 & 33.66 & 64 \\
\hline 11 & 224.58 & 97.02 & 33.66 & 64 \\
\hline 12 & 195.63 & 90.52 & 33.66 & 64 \\
\hline 13 & 198.68 & 85.88 & 31.67 & 64 \\
\hline 14 & 201.77 & 92.11 & 31.67 & 64 \\
\hline 15 & 183.83 & 84.38 & 31.51 & 63 \\
\hline 16 & 178.16 & 84.38 & 33.45 & 63 \\
\hline 17 & 169.94 & 78.59 & 31.51 & 63 \\
\hline 18 & 167.27 & 77.20 & 31.51 & 63 \\
\hline 19 & 147.19 & 75.83 & 31.51 & 63 \\
\hline 20 & 154.47 & 73.14 & 31.51 & 63 \\
\hline 21 & 137.95 & 69.25 & 31.67 & 64 \\
\hline
\end{tabular}

\subsubsection{Hasil Uji Alat di Daerah Teuku}




\begin{tabular}{|l|l|l|l|l|}
\hline 22 & 154.47 & 70.53 & 33.45 & 63 \\
\hline 23 & 156.96 & 81.45 & 31.67 & 63 \\
\hline 24 & 140.21 & 65.54 & 31.67 & 63 \\
\hline 25 & 144.83 & 69.25 & 33.45 & 63 \\
\hline 26 & 152.01 & 98.71 & 33.45 & 63 \\
\hline 27 & 154.47 & 98.71 & 33.45 & 63 \\
\hline 28 & 144.83 & 85.88 & 33.45 & 63 \\
\hline 29 & 129.2 & 61.99 & 33.24 & 62 \\
\hline 30 & 122.95 & 64.34 & 33.24 & 62 \\
\hline 31 & 118.92 & 45.61 & 33.24 & 62 \\
\hline 32 & 116.95 & 56.43 & 33.24 & 62 \\
\hline & $\mathbf{5 1 0 8 . 3}$ & $\mathbf{3 7 4 3 . 4 4}$ & $\mathbf{9 1 9 . 4 4}$ & $\mathbf{1 7 8 5}$ \\
\hline
\end{tabular}

\begin{tabular}{|l|l|l|l|l|}
\hline 8 & 59.72 & 33.62 & 30.15 & 66 \\
\hline 9 & 70.53 & 40.46 & 30.15 & 66 \\
\hline 10 & 48.38 & 24.29 & 30.15 & 66 \\
\hline 11 & 54.32 & 27.73 & 30.03 & 65 \\
\hline 12 & 47.44 & 18.41 & 30.03 & 65 \\
\hline 13 & 53.29 & 18.41 & 29.91 & 64 \\
\hline 14 & 52.28 & 26.54 & 29.91 & 64 \\
\hline 15 & 51.28 & 18.85 & 29.91 & 64 \\
\hline 16 & 38.06 & 18.03 & 29.91 & 64 \\
\hline 17 & 44.72 & 18.44 & 30.03 & 65 \\
\hline 18 & 39.65 & 19.71 & 29.91 & 64 \\
\hline 19 & 54.32 & 22.19 & 29.91 & 64 \\
\hline 20 & 64.34 & 30.46 & 29.91 & 64 \\
\hline 21 & 61.99 & 27.13 & 29.91 & 64 \\
\hline 22 & 54.32 & 29.60 & 29.79 & 63 \\
\hline 23 & 63.16 & 32.92 & 29.79 & 63 \\
\hline 24 & 61.99 & 35.05 & 31.35 & 62 \\
\hline 25 & 64.34 & 39.65 & 31.35 & 62 \\
\hline 26 & 65.54 & 42.97 & 31.35 & 62 \\
\hline 27 & 60.85 & 35.05 & 31.35 & 61 \\
\hline 28 & 48.38 & 20.71 & 31.19 & 61 \\
\hline 29 & 36.53 & 15.16 & 31.35 & 62 \\
\hline 30 & 38.85 & 13.03 & 31.05 & 62 \\
\hline 31 & 42.97 & 15.54 & 31.05 & 62 \\
\hline 32 & 42.12 & 12.05 & 29.79 & 63 \\
\hline 33 & 61.99 & 35.79 & 29.91 & 64 \\
\hline 34 & 74.47 & 42.12 & 31.05 & 62 \\
\hline 35 & 70.53 & 41.28 & 30.03 & 65 \\
\hline 36 & 56.43 & 20.23 & 29.91 & 64 \\
\hline 37 & 47.44 & 22.7 & 29.91 & 64 \\
\hline
\end{tabular}

\subsubsection{Hasil Uji Alat di Daerah Renon}

Alat yang sudah diuji di daerah Lapangan Renon diperoleh berbagai macam nilai suhu dan kadar polusi udara yang telah di deteksi secara realtime. Adapun nilai rata-rata yang didapat yaitu MQ-7: 1196.13 dan MQ135: 1120 Berikut hasil pengujian alat Prototipe Mobile Station untuk Perekaman Kandungan Udara. Hasil pengujian alat di daerah Lapangan Renon dapat dilihat pada Tabel 3.

Tabel 3 Hasil Uji Alat Daerah Renon

\begin{tabular}{|c|c|c|c|c|}
\hline \multirow{2}{*}{ No } & Mq7 & Mq135 & Temp & Hum \\
\cline { 2 - 5 } & $\mathbf{p p m}$ & $\mathbf{p p m}$ & ${ }^{\circ} \mathbf{C}$ & $\mathbf{R H}$ \\
\hline 1 & 69.25 & 42.97 & 31.67 & 64 \\
\hline 2 & 50.30 & 24.29 & 30.03 & 65 \\
\hline 3 & 54.32 & 21.68 & 30.03 & 65 \\
\hline 4 & 50.30 & 20.71 & 30.03 & 65 \\
\hline 5 & 56.43 & 30.89 & 30.15 & 66 \\
\hline 6 & 60.85 & 29.60 & 30.15 & 65 \\
\hline 7 & 64.34 & 37.29 & 30.15 & 66 \\
\hline
\end{tabular}




\begin{tabular}{|c|c|c|c|c|}
\hline 38 & 65.54 & 37.29 & 29.18 & 64 \\
\hline 39 & 59.72 & 25.4 & 29.91 & 64 \\
\hline 40 & 61.99 & 36.53 & 29.18 & 64 \\
\hline 41 & 45.61 & 10.28 & 31.51 & 63 \\
\hline 42 & 60.85 & 32.92 & 29.91 & 64 \\
\hline 43 & 63.16 & 44.72 & 29.79 & 63 \\
\hline & 2444.17 & 1196.13 & 1120 & 2367 \\
\hline
\end{tabular}

\section{Kesimpulan dan Saran}

Hasil penelitian atau pengujian perangkat perekaman kandungan udara menunjukkan bahwa perangkat ini mempunyai fleksibilitas karena tingkat polusi udara dapat diakses secara realtime dan umum. Hasil deteksi gas dan tingkat polusi udara dipantau melalui sebuah halaman web berupa data kandungan gas dan data spasial lokasi kandungan gas tersebut ditransmisikan oleh perangkat mobile.

Belum bisa mengakomodir data spasial apabila perangkat berada di dalam ruangan. Untuk itu perlu dilakukan penelitian lebih lanjut mengenai konektivitas perangkat sehingga bisa memberikan data spasial yang lebih akurat.

\section{Daftar Pustaka}

[1] Agustinus Dkk. 2015 "Rancang Bangun Sistem Pengendali Suhu dan Kelembaban pada Miniatur Greenhouse menggunakan Mikrokontroler Atmega 8"

[2] Faisal. Amri. 2015. Alat Ukur Suhu dan Kelembaban Berbasis Mikrokontroler Atmega 16A dengan menggunakan sensor DHT11

[3] Faroqi, Adam.2017. Perancangan Alat Pendeteksi Kadar Polusi Udara menggunakan Sensor Gas MQ-7 dengan Teknologi Wireless HC-O

4] Sastra, N.P. and Wiharta, D.M., 2016, October. Environmental monitoring as an IoT application in building smart campus of Universitas Udayana. In Smart Green Technology in Electrical and Information Systems (ICSGTEIS), 2016 International Conference on (pp. 85-88). IEEE

[4] Jason. 2010. Pemodelan dan Simulasi Jaringan Sensor Nirkabel Micaz Mote Berdasarkan Standar IEEE 802.15.4

[6] Rizki, F. 2011. Alat Pendeteksi Polusi Udara Dari Gas Karbonmonoksida (CO) pada Ruangan Berbasis Mikrokontroler AT89S51.SURABAYA: UNIVERSITAS ACl Committee 213R-87, (1999), Guide for Structural Lightweight Aggregate Concrete, ACl Committee 213, American Concrete Institut

[7] Sugianto. Azis. 2014. Sistem Pemantauan Kualitas Udara. Bandung Universitas Widyatama.

[8] Situmeang. Asmer Novrianto. 2014. Alat Ukur Kualitas Udara Menggunakan Sensor Gas MQ-135 berbasis Mikrokontroller Atmega16A.

[9] Wibowo. 2012. Tri Widodo. Perancangan Powerbank Berbasis Arduino Leonardo. Teknik. Elektro, Fakultas Tehnik, Universitas Mercubuana. Jakarta, Indonesia. 2012. 